Published in final edited form as:

Health Educ Behav. 2006 February ; 33(1): 97-111.

\title{
Data to Action:
}

\author{
Using Formative Research to Develop Intervention Programs to Increase Physical Activity \\ in Adolescent Girls
}

Deborah Rohm Young, PhD, Carolyn C. Johnson, PhD, Allan Steckler, DrPH, Joel Gittelsohn, PhD, Ruth P. Saunders, PhD, Brit I. Saksvig, PhD, Kurt M. Ribisl, PhD, Leslie A. Lytle, PhD, and Thomas L. McKenzie, PhD

Deborah Rohm Young, University of Maryland, College Park. Carolyn C. Johnson, Tulane

University, New Orleans, Louisiana. Allan Steckler, University of North Carolina, Chapel Hill. Joel

Gittelsohn, Johns Hopkins Bloomberg School of Public Health, Baltimore, Maryland. Ruth P.

Saunders, University of South Carolina, Columbia. Brit I. Saksvig, University of Maryland, Baltimore.

Kurt M. Ribisl, University of North Carolina at Chapel Hill. Leslie A. Lytle, University of Minnesota, Minneapolis. Thomas L. McKenzie, San Diego State University, California.

\section{Abstract}

Formative research is used to inform intervention development, but the processes of transmitting results to intervention planners and incorporating information into intervention designs are not well documented. The authors describe how formative research results from the Trial of Activity for Adolescent Girls (TAAG) were transferred to planners to guide intervention development. Methods included providing oral and written reports, prioritizing recommendations, and cross-checking recommendations with intervention objectives and implementation strategies. Formative work influenced the intervention in many ways. For example, results indicated that middle schools offered only coeducational physical education and health education classes, so the TAAG intervention was designed to be appropriate for both sexes, and intervention strategies were developed to directly address girls' stated preferences (e.g., enjoyable activities, opportunity to socialize) and barriers (e.g., lack of skills, fear of injury) for physical activity. The challenges of using formative research for intervention development are discussed.

\section{Keywords}

formative research; intervention trials; physical activity; adolescents

Formative research is now viewed as a critical step in the development of health behavior change interventions. By assessing individuals' beliefs, perceptions, behaviors, and the environmental structures that may enhance or limit program effectiveness, intervention planners can better design programs to meet local conditions (Gittelsohn et al., 1995). Formative research can also be used to identify subgroups for intervention targeting, including those who are influential in promoting the desired behavior change (Atkin \& Freimuth, 1989). Interventions planned and conducted in a variety of settings with diverse populations have benefited from systematic formative research (Curtis et al., 1997; Gittelsohn et al., 1995; Kumanyika et al., 2003; Mathews, Everett, Binedell, \& Steinberg, 1995; Newes-Adeyi, Helitzer, Caulfield, \& Bronner, 2000; Nichter, Nichter, Thompson, Shiffman, \& Moscicki, 2002).

Address reprint requests to Deborah Rohm Young, PhD, Department of Kinesiology, 2312 Health and Human Performance Building, College Park, MD 20742; phone: (301) 405-2450; fax (301) 405-5578; e-mail: dryoung@umd.edu.. 
How formative research data are actually used in the intervention development process is seldom reported. Because of time and other resource constraints, interventions may be planned simultaneously while collecting formative data on intervention target groups, potentially limiting the ability of formative research information to guide intervention strategies (NewesAdeyi et al., 2000). To serve its intended purposes, formative research data must be analyzed and results made available to intervention planners while the intervention is still under development.

The purpose of this article is to describe how formative research was used to design the Trial of Activity for Adolescent Girls (TAAG) intervention and the challenges intervention designers faced from receiving formative research results in the midst of planning. It also describes the methods used to communicate the formative research information to intervention planners, the perceived utility of the information, and some lessons learned about formative research in multisite trials. By illustrating the processes used and the complexities encountered, other investigators and intervention planners with similar study designs may benefit.

\section{OVERVIEW OF TAAG}

TAAG is a randomized, multicenter field trial of 36 middle schools to test an intervention to reduce the decline in physical activity in adolescent girls. Six field centers (San Diego State University, Tulane University, University of Arizona, University of Maryland, University of Minnesota, and University of South Carolina), a coordinating center (University of North Carolina at Chapel Hill), and the National Heart, Lung, and Blood Institute worked collaboratively to design and conduct the trial. The primary specific aim is to determine if an intervention that provides physical activity opportunities through linking schools to community organizations reduces the age-related decline in moderate to vigorous physical activity in middle school girls. Cross-sectional samples of sixth grade girls in Spring 2003, eighth grade girls in Spring 2005 (to assess primary outcome), and eighth grade girls in Spring 2006 (to assess maintenance effects) were measured to determine the difference in moderate to vigorous physical activity by treatment condition (Stevens et al., 2005).

\section{FORMATIVE RESEARCH}

TAAG investigators were provided with funding for 2 years to plan and conduct measurement and intervention pilot studies prior to the start of the main trial. The formative research plan was developed, implemented, analyzed, and disseminated during this period. Figure 1 illustrates how formative research occurred with respect to intervention planning. The formative research design is explained in detail by Gittelsohn et al. (2006). Briefly, the research plan was based on a social ecologic model that was consistent with the TAAG intervention theoretical framework. The research was guided by examining intrapersonal, interpersonal, organizational, community, and policy-level factors as they pertain to physical activity preferences, opportunities, and challenges for adolescent girls. Formative research investigators worked closely with intervention planners to identify information needs and priorities and develop methods to obtain and disseminate the information.

There were two phases to the formative research. Phase 1 gathered preliminary information from school personnel and from surrounding communities considered to be potential TAAG trial schools. These schools were chosen based on location, average school size, attendance, yearly withdrawal rates, and racial and ethnic minority representation. Phase 2 was conducted as the interventionists identified additional areas in which more information was needed to refine the intervention. Data for Phase 2 were collected in the 36 schools participating in the main trial and from additional adolescents from non-TAAG main trial schools. TAAG school eligibility requirements included being of public middle schools in which the majority of students were from the local community, enrollment of at least 90 girls in the eighth grade, 
experience no more than a $28 \%$ yearly transient rate, and required physical education in all grades. University institutional review board approval from all six field sites, parental consent, and child assent were obtained. All instruments and data collection methods were pretested and modified prior to national data collection training.

\section{Phase 1: Initial Information Gathering}

School Survey-Middle school principals or their designee were interviewed at all potential TAAG schools ( $n=64 ; 93 \%$ response rate) to obtain information on the school's physical education and health education requirements, physical activity facilities and programs, transportation issues, relationships with community organizations, and availability and use of the Internet by school personnel and students.

Community Agency Survey-Community agencies that had a physical facility, offered physical activity programs or services, and could serve girls from potential TAAG schools were surveyed to determine information about current physical activity programming. Directors, managers, coordinators, or other key personnel responsible for youth programs were mailed surveys. The 23-item instrument included questions about the types of physical activity programs offered during different months or seasons, typical attendance by middle-schoolaged girls, type of facilities available, staffing requirements, marketing methods for programming, and availability and use of the Internet. Surveys were mailed out to 248 agencies, with a range of 22 to 74 surveys mailed per field site. Of these, 138 were returned (56\% overall response rate; range per site was $29 \%$ to $81 \%$ ).

Parent Survey-Parents of seventh and eighth grade girls were invited to participate in a telephone interview regarding physical activity and their daughter. Parents received a letter explaining the study and informing them they would be contacted. Because of middle school policies and institutional review board restrictions, at some sites, post cards were sent to parents with a mail-back section that parents signed granting permission to be interviewed prior to telephone contact. At other sites, TAAG staff directly telephoned parents and requested verbal permission to conduct the interview. The 29-item interview was designed to determine parents' perceptions of their daughter's physical activity levels, access to physical activity resources and programs, barriers to participating in physical activity, and family participation in physical activity. Approximately 230 parents were approached to be interviewed; 87 were interviewed (38\% response rate). Response rate was lower at sites that required a written permission prior to making contact with parents.

Girls' Activity Checklist-Girls in the sixth and eighth grade attending required subject classes were approached to obtain parental consent to administer a brief survey to determine their favorite physical activities and current participation in activities. The survey consisted of a checklist of 56 physical activities in which the girls marked the activities they had participated in the prior 7 days and that were most appealing to them. A total sample of 130 girls participated (sites ranged between 14 and 31 girls).

Girls' Semistructured Interviews-Eighty seventh and eighth grade girls (8 to 21 girls per site) were interviewed in a semistructured format to determine favorite physical activities, attitudes about physical education class, factors influencing their physical activity level, and existing barriers to physical activity. Teachers were asked to identify girls of varying racial and ethnic backgrounds who had a variety of physical activity levels, who were representative of the school, and who would likely be able to speak freely in this setting. Girls were subsequently directly contacted to ascertain interest in participating in the study and to obtain parental consent. 


\section{Phase 2: Information Gathering to Refine Intervention}

Boys' Focus Groups-Seventy-seven boys in sixth, seventh, and eighth grade of diverse ethnic and racial groups participated in 12 focus group discussions. Similar to the girls' semistructured interviews, teachers identified those boys who would be able to participate in this format and who were representative of boys at their school. Discussion topics included their perceptions about girls being physically active and girls' participation in physical education class and after-school physical activity.

Girls' Focus Groups-To determine the acceptability of proposed intervention strategies, 100 seventh and eighth grade girls of diverse ethnic and racial groups participated in 13 focus groups. Teachers identified representative participants to provide ideas for promotional contests and competitions, message channels for intervention materials, and reactions to potential logos, graphic design elements, and taglines (i.e., theme messages). The girls also were asked to speculate on the physical activity messages and message channels preferred by various social segments (defined by the girls, e.g., preppy girls, girly girls) at their school.

Physical Education Teacher Interviews-Physical education department heads at all 36 main trial middle schools (100\% response rate) were interviewed to determine teaching methods, available resources, physical education strategies for girls, and barriers they encountered in implementing their district's physical education curriculum.

\section{DATA ANALYSIS}

Data were analyzed using either quantitative or qualitative approaches, which are described in detail in Gittelsohn et al. (2006) and Vu, Murrie, Gonzalez, \& Jobe (2006). Frequencies of response items were calculated, and data were compared across sites and ethnic and racial groups, where appropriate. Answers to open-ended questions were compiled and assessed for common themes. Qualitative data were transcribed, coded, and analyzed using Qualitative Solutions and Research N6 software. Convergent and divergent themes were identified and tabulated. Data from all sites were compiled for reporting purposes, except when site-specific variations warranted stratified reporting.

\section{FORMATIVE RESEARCH RESULTS}

The results of formative research are presented in detail in other work published in this supplement (Grieser et al., 2006; Moe et al., 2006; Saunders \& Moody, 2006; Staten, Birnbaum, Jobe, \& Elder, 2006; Vu et al., 2006). There were, however, some key findings that had overarching implications for intervention planning. These included the following: (a) Girls prefer physical activities that are fun; (b) most schools provided health education and physical education classes in coeducational settings; (c) family members were viewed by girls, parents, and school administrators to be the most important influence on girls' physical activity levels; and (d) considerable variability occurred within and between sites with respect to resources, accessibility, and specific types of physical activity programming.

\section{DISSEMINATING FORMATIVE RESEARCH RESULTS}

The TAAG formative research working group used multiple avenues to disseminate the results. These included (a) interim presentations at national-level project investigator meetings, (b) verbal reports of results in intervention working groups' planning conference calls and meetings, (c) written reports specifying recommendations for intervention planners to consider, (d) informal verification of how intervention development incorporated formative assessment recommendations, (e) formal interim written reports, and (f) a final written report summarizing all results. Interim presentations were made, on average, 2 months after completion of data 
collection. Written reports that included more detailed analyses followed 2 to 4 months after the presentations. All reports were posted on the TAAG internal Web site; hard copies of written reports also were provided to all field sites. Whenever possible, results were integrated across data collection instruments to provide convergent and divergent information from the different sources. Specifics of each dissemination method are described below.

\section{Interim Presentations}

Investigators met face to face approximately every 2 months during the planning phase of the trial. During these meetings, 45- to 60-min presentations were given to summarize the formative assessment results to date. Data provided in the interim presentations were consistent with final reports, although the interim reports provided less detail. Nonetheless, they provided intervention planners with needed information.

\section{Intervention Working Groups' Reports}

Intervention working groups had a standing agenda item for formative research representatives to orally report on pertinent results. Because intervention working groups typically had biweekly conference calls, results were reported to intervention planners quickly.

\section{Intervention Recommendation Reports}

The formative research working group prepared written summaries of key results and recommended ways in which they could be addressed during the intervention. Reports were generated in succinct, memorandum form designed to be easy to read. These recommendations are displayed in Tables 1 to 4 and are discussed below.

\section{Written Reports}

Interim and final reports were prepared and delivered to intervention planners and steering committee members. They also were posted on the TAAG Web site so all investigators and staff could access the documents. To increase use of the reports, an executive summary of key results and recommendations was provided, followed by detailed results and recommendations that included the overall and site-specific data tables and textual data.

As an example of how the methods described above were used, Figure 1 displays how formative research results were disseminated to the intervention planners. It also illustrates how formative research and intervention planning was simultaneously occurring.

\section{TAAG INTERVENTION}

The TAAG intervention was based on a social-ecological model and targeted intrapersonal, interpersonal, organizational, and environmental factors that influence physical activity behavior. It focused on increasing girls' levels of physical activity by increasing opportunities to be active through structured activities (e.g., programs, lessons) in school (including physical education class and other times during the school day), through structured activities outside the regular school day (including programs occurring on and off the school grounds and during the weekends and summer), and through an increase in unstructured activities (e.g., walking, cycling) in a variety of settings (including home, school, and in the community).

The intervention consisted of four major components designed to work in synergy to provide supportive environments for girls' physical activity.

1. TAAG Physical Education. Physical education teachers attended workshops and received instructional materials and regular on-site support to conduct lessons that promoted full participation of girls. 
2. Health Education and Activity Challenges. Health education, physical education, science, or homeroom teachers attended workshops and received materials to teach a series of lessons that promoted development of behavioral skills associated with physical activity.

3. Programs for Physical Activity (PPA). Collaborations were created between schools, community agencies, and the TAAG universities to increase activity programs outside of school.

4. Promotions. Activities were launched to encourage overall physical activity and promote TAAG-specific programs through posters, flyers, and campaigns.

\section{HOW FORMATIVE RESEARCH GUIDED INTERVENTION DEVELOPMENT}

In response to general formative research results previously listed, the TAAG intervention was developed. In general, it was designed to maximize the fun and enjoyable aspects of physical activity. The curriculum-based intervention components (i.e., physical education, health education) were structured for both single-sex and coeducational settings. The PPA component was designed to be flexible to accommodate variability in school- and community-level resources. Additionally, information about TAAG lessons, activities, and programs were supplied to families through multiple sources (e.g., school newsletters, flyers). Formative research results used for the specific intervention components are described below.

\section{Physical Education Component}

Results from formative research indicated that physical education was provided in a variety of ways, as detailed by Moe et al. (2006). TAAG physical education was thus developed as a philosophical approach to engage students of varying interests and physical abilities by teaching quality physical education rather than as a designated curriculum. It was designed to be flexible to meet all formats in which physical education may be taught and to be relevant to boys as well as girls. Table 1 lists specific formative research recommendations given to guide the physical education component. The intervention did not directly target policy recommendations. Formative research results indicated that almost all those teaching physical education were certified physical education specialists, so staff development workshops were oriented toward that audience. Semistructured interviews indicated that girls enjoyed physical education classes more when the teachers participated in the activities with them. Staff development workshops and print materials encouraged teachers to serve as positive role models by participating with students and talking with them about personal physical activity involvement.

Formative results indicated that girls wanted to be able to make choices during their physical education classes; hence, the TAAG physical education component placed a major emphasis on providing choice. Options for allowing choices among activities, skill level, and group memberships were modeled during the workshops and presented in print materials. For example, lessons were modeled to illustrate how students could select different skill levels of a sport or game or choose the type of equipment to use (i.e., for volleyball, the choice to use a beach ball, trainer, or standard ball).

Finally, formative research data indicated that many girls were attracted to cooperative, noncompetitive activities. Staff development workshops included demonstrations of activities that promoted peer cooperation and how to structure other activities to be noncompetitive. Sample activities included jump bands, step aerobics, dance and rhythm, and stunts and tumbling. 


\section{Health Education and Activity Challenges Intervention Component}

Formative research indicated that health education was taught in health education, physical education, science, or family studies classes and was likely to be delivered in a coeducational setting. Formative research recommendations were made to provide flexibility in formats to accommodate this variation. For instance, two versions of each lesson were developed to maximize flexibility: One could be delivered in a traditional classroom setting, and the other was designed for open space (physically active) environments, such as physical education class. Because results indicated that family was an important influence on girls'activity, lesson content included family aspects of physical activity, such as developing negotiation, communication, and social support skills.

Table 2 identifies specific recommendations based on formative research results, categorized into training, format, and opportunities topics. Staff development workshops were designed in a manner so teachers from a variety of subject specialties would be able to successfully teach the lessons. Lesson topics were selected based on extensive literature reviews to identify the most important educational and behavioral topics relevant to physical activity levels of adolescent girls. However, developing these topics into salient lesson content was guided by formative research results. For example, several activity challenges could be completed with family members, and the sample activities used in the lessons and print materials were ones the girls reported as fun.

\section{PPA Intervention Component}

Table 3 identifies intervention recommendations grouped into availability, variety, accessibility, support, and enhancements categories. Formative research results indicated that there were opportunities for additional programs during evenings, weekends, school breaks (e.g., spring break), and summers. Most available programs were sports oriented, resulting in the recommendation to offer more variety in the types of programs offered. Providing transportation, promoting other existing transportation sources, and reducing costs of programs were accessibility-related recommendations. Disseminating information to families about new and existing programs was also suggested. Finally, recommendations to enhance existing programs included providing more activity program choices and ensuring safe environments.

The PPA component included developing a summary report that described existing programs in intervention schools' catchment areas created to be shared with school and community stakeholders. This report was largely based on local formative research data and was used to highlight opportunities for promoting high-quality existing programs and for developing new programs where gaps existed. Because it was necessary to structure PPA with sufficient flexibility to be able to build on existing strengths in the various communities, most formative research recommendations were incorporated at the individual site level.

\section{Promotions Intervention Component}

As displayed in Table 4, formative research recommendations were summarized into the following categories: general, family, girls, boys, and school. These recommendations primarily focused on how to create messages and promotional materials to reach the target groups. Approximately 20 potential "taglines" were tested in the focus groups. "Real Girls, Real Activities, Real Fun" was chosen for use in promotional posters and flyers because it was the one that was most positively received by the target audience. Promotional print materials depicted girls of varying body sizes, hair and dress style, and racial and ethnic groups having fun doing a variety of activities ranging from unstructured activities, such as walking, to sports activities, such as field hockey. Many photographs used in the posters showed girls in groups to emphasize the social aspect of physical activity. Promotional challenges were also developed for each grade level, based on formative assessment results that suggested grade-specific 
activities were preferred. For example, a "Physical Activity Passport Program" was developed to encourage and reward seventh grade girls for participating in a variety of physical activities. A Pedometer Challenge was designed for eighth grade girls that allowed classrooms to compete against each other to attain the highest average step count.

\section{Successes and Challenges of Sharing Formative Research With Intervention Planners}

A primary success of TAAG formative research was its utility in assuring that the intervention was applicable across the varied geographical sites and at the specific schools. For example, during the early planning stage, it was thought that physical education class could be delivered in a girls-only format. Formative research results indicated that this strategy would not have been acceptable to many schools. Incorporating formative research results into the intervention components assured site investigators that the intervention, as planned, could be successfully implemented.

There were notable challenges in developing and implementing a process of disseminating information to intervention planners. Briefly, significant challenges that we faced were (a) the need for intervention planning to get started concurrently with formative research planning and data collection, resulting in formative research that was sometimes a step behind intervention development; (b) the inability to collect some formative research data in actual TAAG schools because of concerns of potentially sensitizing families, girls, and schools prior to the start of the intervention; (c) the preference for analyzing data across sites, which provided limited information at the individual school level; and (d) differences in each site's institutional review board requirements that delayed formative data collection.

\section{Lessons Learned Through TAAG Formative Research}

Valuable lessons were learned during the TAAG formative research. These include the following: (a) Collaboration and frequent communication between formative research planners and intervention planners is essential when intervention development is occurring simultaneously with formative research data collection; (b) quick development of formative research plans, instrument development, data collection, and turnaround of results is essential to adequately inform intervention planners; (c) multiple sources of data collection that include persons tangential to the target audience yield rich data useful for intervention planning; and (d) site-level institutional review board delays must be included in realistic timelines.

\section{DISCUSSION}

Large, multicenter intervention trials are complex, which can lead to a number of groups working independently with the potential of limited information sharing. Documenting how formative research helped develop the TAAG intervention may be useful for other groups planning to develop interventions. It can also be useful for practitioners who conduct formative research prior to creating interventions. The TAAG experience illustrates how formative research can be designed to meet needs for intervention planning, how information can be transferred to intervention planners in a timely fashion, and how recommendations can be incorporated into intervention plans.

Although TAAG had 2 years to plan the intervention protocol, it was still challenging. Formative research priorities had to be established, and data needed to be gathered, summarized, and disseminated to intervention planners in a timely fashion. At the same time, the intervention was being developed and materials being created for the pilot intervention. Formative research planners incorporated multiple forms of feedback to ensure that the data collected would be useful. The combination of informal and formal systems of reporting provided prompt feedback of information. Previously published formative research conducted 
for intervention planning purposes have not conveyed strategies for dissemination (Curtis et al., 1997; Kumanyika et al., 2003; Mathews et al., 1995; Newes-Adeyi et al., 2000), so the work presented in this article addresses an existing gap in the literature.

Even with multiple channels being used to disseminate information, intervention planners did not always feel they received the information early enough. When insufficient time is allowed between collecting formative research data and intervention planning, there is a risk of sharing incomplete data that do not hold up in final analyses. Others operating under similar tight time constraints may wish to consider decentralizing data analysis so individual sites may have access to necessary information. However, decentralization can lead to other problems, such as potential data analysis inefficiencies, quality control issues, and lack of across-site data analysis standardization. An alternate strategy is to sequence intervention development to follow formative research data collection. Finally, acknowledging the amount of time needed to adequately plan and execute formative research by funding longer planning phases would be ideal.

There are limitations in using formative research to plan interventions. Sampling strategies may not yield representative participants, and thus, inaccurate conclusions may be reached. Poor response rates for some of the surveys (e.g., parent surveys, community surveys) may also have biased our results. Our methods may not have been the most appropriate for the information we were trying to obtain. For example, the community survey provided us with information about programming at those agencies, but we did not obtain information from numerous for-profit organizations that exist in communities.

\section{Implications for Practitioners}

By documenting the multiple strategies TAAG used to transmit information to intervention planners, other groups with similar needs for sharing formative research can benefit. Building multiple systems to share information into the overall formative research plan can ensure that the information is received in a timely manner. Even so, others may wish to consider additional strategies, such as sequencing formative research data collection with intervention development, to provide important information to intervention planners faster. These strategies can be useful to practitioners as well as researchers who conduct formative research.

\section{CONCLUSION}

In conclusion, the formative research approach used by TAAG employed a variety of strategies to collect data and to disseminate findings to intervention planners, which was then used to develop a relevant intervention to reduce the decline of physical activity in adolescent girls. Future studies can explore similar methods to ensure formative research results are incorporated into intervention planning.

\section{Acknowledgements}

This work was funded by National Institutes of Health Grants U01HL66845, U01HL66852, U01HL66853, U01HL66855, U01HL66856, U01HL66857, and U01HL66858. The authors acknowledge the contributions of Mr. Derek Coombs, Ms. Mira Grieser, Ms. Stacey Moe, Ms. Jamie Moody, Ms. Dale Murray, Ms. Julie Pickrel, Dr. Charlotte Pratt, Dr. Lisa Staten, Ms. Dawn Stewart, and Dr. Maihan Vu.

\section{References}

Atkin, C.; Freimuth, V. Formative evaluation research in campaign design. In: Rice, RE.; Atkin, CK., editors. Public communication campaigns. 2nd ed.. Sage; Newbury Park, CA: 1989. p. 131-150.

Curtis V, Kanki B, Cousens S, Sanou A, Diallo I, Mertens T. Dirt and diarrhoea: Formative research in hygiene promotion programmes. Health Policy Planning 1997;12:122-131. 
Gittelsohn J, Harris SB, Whitehead S, Wolever TMS, Hanley AJG, Barnie A, et al. Developing diabetes interventions in an Ojibwa-Cress community in Northern Ontario: Linking qualitative and quantitative data. Chronic Diseases of Canada 1995;16:157-164.

Gittelsohn J, Steckler A, Johnson CC, Pratt C, Grieser M, Pickrel J, et al. Formative research in school and community-based health programs and studies: "State of the art" and the TAAG approach. Health Education \& Behavior 2006;33:25-39. [PubMed: 16397157]

Grieser M, Vu MB, Bedimo-Rung AL, Neumark-Sztainer D, Moody J, Young DR, et al. Physical activity attitudes, preferences, and practices in African American, Hispanic, and Caucasian girls. Health Education \& Behavior 2006;33:40-51. [PubMed: 16397158]

Kumanyika SK, Story M, Beech BM, Sherwood ND, Baranowski JC, Powell TM, et al. Collaborative planning for formative assessment and cultural appropriateness in the Girls Health Enrichment Multisite Studies (GEMS): A retrospection. Ethnicity and Diseases 2003;13:S1-15-S1-29.

Mathews C, Everett K, Binedell J, Steinberg M. Learning to listen: Formative research in the development of AIDS education for secondary school students. Social Science and Medicine 1995;41:1715-1724. [PubMed: 8746871]

Moe SG, Pickrel J, McKenzie TL, Stikmiller PK, Coombs D, Murrie D. Using school-level interviews to develop a multisite PE intervention program. Health Education \& Behavior 2006;33:52-65. [PubMed: 16397159]

Newes-Adeyi G, Helitzer DL, Caulfield LE, Bronner Y. Theory and practice: Applying the ecological model to formative research for a WIC training program in New York State. Health Education Research 2000;15:283-291. [PubMed: 10977376]

Nichter M, Nichter M, Thompson PJ, Shiffman S, Moscicki B. Using qualitative research to inform survey development on nicotine dependence among adolescents. Drug Alcohol Dependence 2002;68:S41S56.

Saunders RP, Moody J. Community agency survey formative research results from the TAAG study. Health Education \& Behavior 2006;33:12-24. [PubMed: 16397156]

Staten LK, Birnbaum AS, Jobe JB, Elder JP. A typology of middle school girls: Audience segmentation related to physical activity. Health Education \& Behavior 2006;33:66-80. [PubMed: 16397160]

Stevens J, Murray DM, Catellier DJ, Lytle LA, Elder JP, Young DR, et al. Design of the trial of activity in adolescent girls (TAAG). Contemporary Clinical Trials 2005;26:223-233. [PubMed: 15837442]

Vu MB, Murrie D, Gonzalez V, Jobe JB. Listening to girls and boys talk about girls' physical activity behaviors. Health Education \& Behavior 2006;33:81-96. [PubMed: 16397161] 


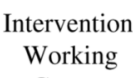

Research Working Group

Intervention
Development

Timeline

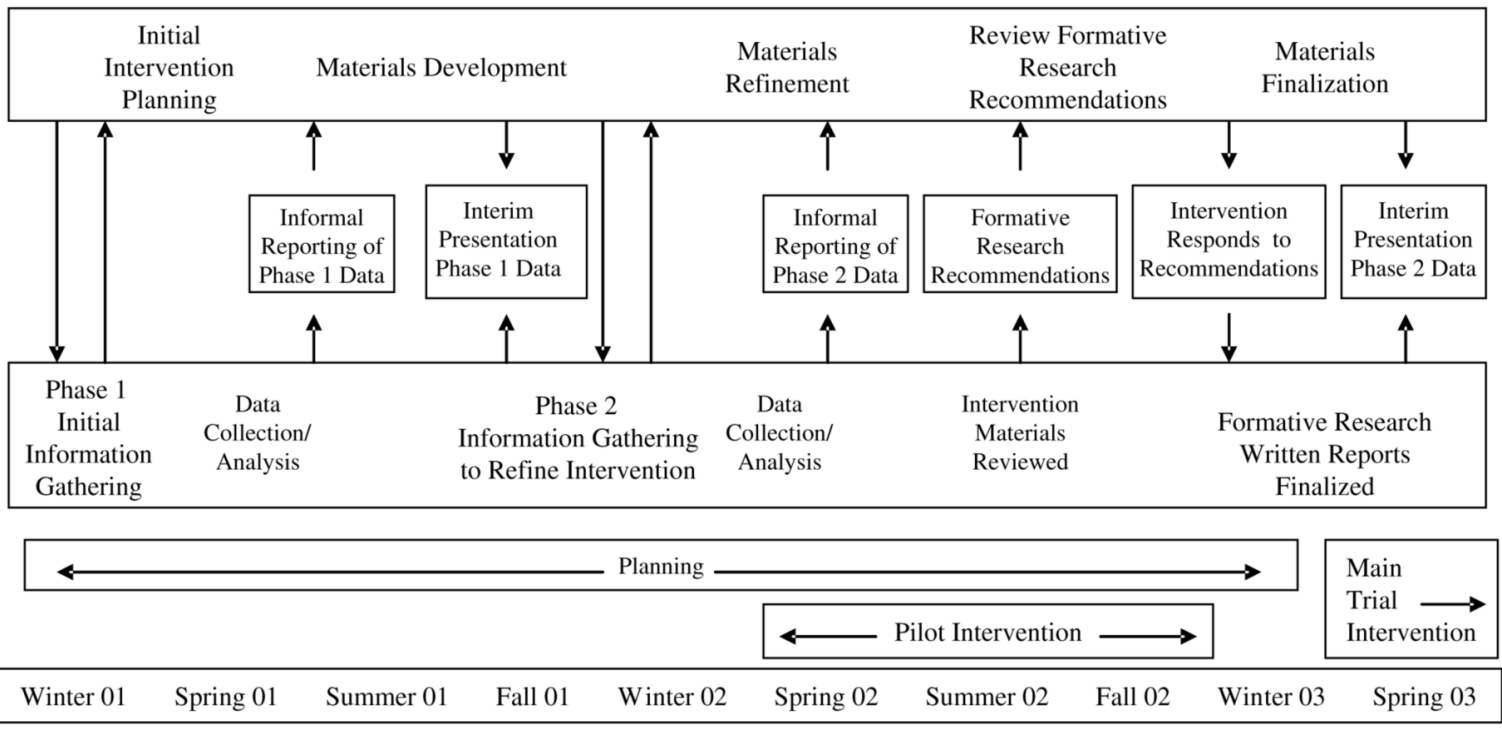

Figure 1.

TAAG formative research dissemination process with intervention planning. NOTE: TAAG = Trial of Activity for Adolescent Girls. 
Table 1

Formative Research Recommendations for the TAAG Physical Education (PE) Component

\begin{tabular}{ll}
\hline Category & Recommendation \\
\hline Policy & $\begin{array}{l}\text { Negotiate with schools to increase amount of PE offered or required. } \\
\text { Encourage school policy changes to ensure alternatives to PE class are not available (e.g., interscholastic sports instead of PE } \\
\text { class). }\end{array}$ \\
Orient PE intervention training to certified PE teachers. \\
Include part-time and assistant PE teachers in TAAG PE training. \\
Advise PE teachers to participate in activities with girls when appropriate, leading by example. \\
Encourage schools to offer choice of girls-only and coed PE classes. \\
Offivities \\
Format choice of activities during PE classes in school that would appeal to girls with different preferences. \\
Develop a PE intervention that can work in a variety of formats, including 2 to 5 days per week, one or two semesters per year, \\
and class periods ranging from 45 to 90 min. \\
Develop PE unit activities appropriate for girls in several grades. \\
Ensure that in-class exercises that emphasize strength and endurance (e.g., pushups and sit-ups) are conducted in a fun manner. \\
Limit lecturing and required note taking in PE. \\
Ensure competition between boys and girls is conducted in a healthy manner.
\end{tabular}

NOTE: $\mathrm{TAAG}=$ Trial of Activity for Adolescent Girls 
Table 2

Formative Research Recommendations for the TAAG Health Education and Activity Challenges Component

\begin{tabular}{|c|c|}
\hline Category & Recommendation \\
\hline Staff development & $\begin{array}{l}\text { Plan staff development to accommodate teachers of different specialties (e.g., physical education, health education, } \\
\text { science). }\end{array}$ \\
\hline \multirow{7}{*}{ Format } & Design flexible lessons that can be implemented in a variety of classes. \\
\hline & Provide opportunities for discussion among girls and teachers in the lessons. \\
\hline & Use activity challenges to encourage family members to engage in physical activity with the girls. \\
\hline & Use girls' favorite and most common activities in lesson content. \\
\hline & $\begin{array}{l}\text { Address barriers that girls perceive for physical activity (e.g., social barriers from boys and some family members, } \\
\text { transportation, lack of time, homework, jobs or chores, cost). }\end{array}$ \\
\hline & Promote developing skills and knowing rules to avoid injury. \\
\hline & Promote discussion that muscle soreness can be a natural result from becoming more active. \\
\hline \multirow[t]{2}{*}{ Opportunities } & Include activities that girls can participate in during unstructured time. \\
\hline & Identify ways for girls to make childcare and chores more active. \\
\hline
\end{tabular}

NOTE: TAAG = Trial of Activity for Adolescent Girls. 
Table 3

Formative Research Recommendations for the TAAG Physical Activity Programs

\begin{tabular}{|c|c|}
\hline Category & Recommendation \\
\hline Availability & $\begin{array}{l}\text { Work with community agencies to offer more programs during evenings, weekends, summer, and school breaks. } \\
\text { Offer a wide range of activities after school. }\end{array}$ \\
\hline Variety & $\begin{array}{l}\text { Offer different categories of activities that will appeal to girls with different activity preferences (e.g., sports, noncompetitive, } \\
\text { social, unstructured, girls only, coed). } \\
\text { Explore ways to encourage and/or provide activity for girls doing childcare. }\end{array}$ \\
\hline Accessibility & $\begin{array}{l}\text { Promote the use of activity buses in schools. } \\
\text { Explore possibility of scheduling buses to stop at off-site physical activity locations. } \\
\text { Suggest ways for community agencies to encourage and/or support parents in getting girls to and from activities. } \\
\text { Suggest ways to subsidize, reduce, or waive user fees. }\end{array}$ \\
\hline Support & $\begin{array}{l}\text { Develop communication systems with girls and parents through flyers and school newsletters that include safety and training } \\
\text { information, ways to encourage unstructured family activities, and ways for parents to encourage indoor activities for girls } \\
\text { with after-school family duties. } \\
\text { Provide opportunities for families to visit recreational facilities to observe programs. }\end{array}$ \\
\hline Enhancements & $\begin{array}{l}\text { Provide training to optimize the appeal of programs for girls. Example training topics include offering activity choice, } \\
\text { dispelling myths that girls are only interested in certain activities (e.g., cheerleading). Encourage positive social interactions. } \\
\text { Provide environments in which girls feel safe and are not fearful of being injured. }\end{array}$ \\
\hline
\end{tabular}

NOTE: TAAG = Trial of Activity for Adolescent Girls. 
Table 4

Formative Research Recommendations for TAAG Promotions

\begin{tabular}{|c|c|}
\hline Category & Recommendation \\
\hline General & $\begin{array}{l}\text { Develop a recognizable and unifying theme. } \\
\text { Target intervention activities to specific grade levels. } \\
\text { Use lunch periods as a time to promote interventions. }\end{array}$ \\
\hline Family & $\begin{array}{l}\text { Develop materials to encourage parents and family members to engage in activities with the girls. } \\
\text { Develop an informational component for parents that reinforce what girls are learning in school. } \\
\text { Use multiple communication methods to reach parents. }\end{array}$ \\
\hline Girls & $\begin{array}{l}\text { Promote the social aspects of doing TAAG activities with a friend. } \\
\text { Convey the messages that girls viewed as important reasons for engaging in physical activity (e.g., fun, time to be social). } \\
\text { Develop linkages with community resources to encourage girls to take advantage of summer activities. } \\
\text { Develop activities that reach girls through their e-mail accounts. }\end{array}$ \\
\hline $\begin{array}{l}\text { Boys } \\
\text { School }\end{array}$ & $\begin{array}{l}\text { Develop messages that promote girls being active as normal and positive and something that boys should support. } \\
\text { Encourage schools to facilitate physically active transportation, such as putting in bicycle racks. }\end{array}$ \\
\hline
\end{tabular}

NOTE: TAAG $=$ Trial of Activity for Adolescent Girls. 